ARTICLE

https://doi.org/10.1038/s41467-022-28436-z

\title{
Unraveling the rate-limiting step of two-electron transfer electrochemical reduction of carbon dioxide
}

Wanyu Deng ${ }^{1,2}$, Peng Zhang ${ }^{1,3}$, Brian Seger (id ${ }^{2 凶} \&$ Jinlong Gong (1) 1,3凶

Electrochemical reduction of $\mathrm{CO}_{2}\left(\mathrm{CO}_{2} \mathrm{ER}\right)$ has received significant attention due to its potential to sustainably produce valuable fuels and chemicals. However, the reaction mechanism is still not well understood. One vital debate is whether the rate-limiting step (RLS) is dominated by the availability of protons, the conversion of water molecules, or the adsorption of $\mathrm{CO}_{2}$. This paper describes insights into the $\mathrm{RLS}$ by investigating $\mathrm{pH}$ dependency and kinetic isotope effect with respect to the rate expression of $\mathrm{CO}_{2}$ ER. Focusing on electrocatalysts geared towards two-electron transfer reactions, we find the generation rates of $\mathrm{CO}$ and formate to be invariant with either $\mathrm{pH}$ or deuteration of the electrolyte over $\mathrm{Au}, \mathrm{Ag}$, $\mathrm{Sn}$, and In. We elucidate the RLS of two-electron transfer $\mathrm{CO}_{2} \mathrm{ER}$ to be the adsorption of $\mathrm{CO}_{2}$ onto the surface of electrocatalysts. We expect this finding to provide guidance for improving $\mathrm{CO}_{2} \mathrm{ER}$ activity through the enhancement of the $\mathrm{CO}_{2}$ adsorption processes by strategies such as surface modification of catalysts as well as careful control of pressure and interfacial electric field within reactors.

\footnotetext{
${ }^{1}$ Key Laboratory for Green Chemical Technology of Ministry of Education, School of Chemical Engineering and Technology, Tianjin University, Collaborative Innovation Center of Chemical Science and Engineering (Tianjin), Tianjin 300072, China. ${ }^{2}$ SurfCat, Department of Physics, Technical University of Denmark, 2800 Kgs Lyngby, Denmark. ${ }^{3}$ Joint School of National University of Singapore and Tianjin University, International Campus of Tianjin University, Binhai New

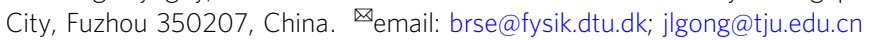


$\mathrm{n}$ order to alleviate greenhouse effects, countries around the world have formulated different carbon neutralization plans ${ }^{1}$. Electrochemical reduction of $\mathrm{CO}_{2}\left(\mathrm{CO}_{2} \mathrm{ER}\right)$ can convert $\mathrm{CO}_{2}$ into valuable fuels and chemicals ${ }^{2-7}$, which is an emerging approach to utilize $\mathrm{CO}_{2}$ as a resource. $\mathrm{CO}_{2} \mathrm{ER}$ to either $\mathrm{CO}$ or formate through the two-electron transfer reaction is promising for industrialization due to its high selectivity and high current density ${ }^{8,9}$. An in-depth understanding of the two-electron transfer reaction mechanisms is, therefore, essential to designing high-efficiency catalysts and advancing the progress of $\mathrm{CO}_{2}$ ER towards commercialization.

Recently, the two-electron transfer of $\mathrm{CO}_{2} \mathrm{ER}$ to formate and $\mathrm{CO}$ has been widely accepted to proceed through the pathways with intermediate species of ${ }^{*} \mathrm{OOCH}$ and ${ }^{*} \mathrm{COOH}$, respectively ${ }^{10,11}$, as inner-sphere electron-transfer reactions ${ }^{12,13}$. However, there is still a debate in terms of the RLS ${ }^{14-16}$. Specifically, the RLS has been considered to be the adsorption of $\mathrm{CO}_{2}$ along with an electron transfer over the catalysts ${ }^{17-21}$, the transfer of protons to ${ }^{*} \mathrm{CO}_{2}{ }^{-}$to form ${ }^{*} \mathrm{COOH}$ or $* \mathrm{OOCH}^{16,22,23}$, the proton-coupled electron transfer to form $* \mathrm{COOH}$ or $* \mathrm{OOCH}^{24}$, or the desorption of $* \mathrm{CO}^{25,26}$ according to the results of Tafel analysis ${ }^{16,17,22}$, reaction order analysis ${ }^{20,21}$, and theoretical calculations ${ }^{25,26}$. These methods adopted previously may fail to recognize the correct RLS due to experimental errors or insufficient precision. For the Tafel analysis, it is hard to tell the RLS in $\mathrm{CO}_{2} \mathrm{ER}$ filed due to mass transport limitations ${ }^{16}$ and the value assumed for the transfer coefficient $(\alpha)^{27}$. Because the theoretical Tafel slope might be incorrect due to the improper assumption of 0.5 transfer coefficient which might lead to a wrong guidance for the RLS ${ }^{27}$. The reaction order analysis used to determine whether the RLS includes a proton transfer step is often performed by changing the $\mathrm{pH}$ of the electrolyte ${ }^{28,29}$. It is an incomplete approach because the source of protons may come from water molecules instead of $\mathrm{H}^{+[30}$, where the activity of $\mathrm{CO}_{2} \mathrm{ER}$ would not change with $\mathrm{pH}$. On the other hand, the RLS without proton transfer may still change with $\mathrm{pH}$ if the proton transfer step occurs before the RLS. Although theoretical calculations have widely been adopted to find the RLS, the reliability of the results greatly depends on the choice of models and experimental methods ${ }^{31,32}$. Therefore, it is of great significance to also develop a reliable experimental strategy to reveal the RLS for $\mathrm{CO}_{2} \mathrm{ER}$.

In this work, theoretical derivations and experimental results are combined and discussed in detail to provide sufficient evidence for the determination of the RLS during the two-electron transfer $\mathrm{CO}_{2} \mathrm{ER}$. The rate expressions with different RLSs were first derived through the breakdown of the Butler-Volmer equation. By analyzing these rate expressions, an effective method for discovering the RLS was proposed, which combines $\mathrm{pH}$ dependency and kinetic isotope effect (KIE) experiments. Since $\mathrm{H}^{+}$ions and $\mathrm{H}_{2} \mathrm{O}$ molecules are both proton donors, the reaction orders of $\mathrm{H}^{+}$and $\mathrm{H}_{2} \mathrm{O}$ can be obtained by changing the $\mathrm{pH}$ of the electrolyte and the adoption of $\mathrm{D}_{2} \mathrm{O}$ in the electrolyte. Corresponding results could help clarify whether the adsorption of $\mathrm{CO}_{2}$ with its concomitant electron transfer (ET) step or the other possible steps, such as the proton transfer (PT), proton-coupled electron transfer (PCET), or desorption (D) of product, is the RLS. Subsequently, Au, Ag, Sn, and In were used as model catalysts to reveal the RLS of the twoelectron transfer $\mathrm{CO}_{2} \mathrm{ER}$. For all the electrocatalysts, the current densities of $\mathrm{CO}\left(j_{\mathrm{CO}}\right)$ and formate $\left(j_{\mathrm{HCOO}-}\right)$ are independent of both $\mathrm{pH}$ and deuteration of the electrolyte, which indicates the $\mathrm{CO}_{2}$ adsorption step to be the RLS.

\section{Results}

The rate expressions with different reaction steps as the RLS. In order to discover the RLS, the Butler-Volmer equation was employed to describe the kinetic rate expression of two-electron transfer $\mathrm{CO}_{2} \mathrm{ER}$. It describes how the electrical current passing through an electrode depends on the voltage difference between the electrode and the bulk electrolyte for simple unimolecular redox reactions, when both a cathodic and an anodic reaction proceeding on the same electrode are controlled by surface reactions rather than the mass transfer of electrolyte ${ }^{33}$. For electroreduction reactions (Eq. 1, where $\mathrm{O}_{x}$ and $\mathrm{R}_{\mathrm{ed}}$ represent oxidant and reductant, respectively), the Butler-Volmer equation is shown as Eq. $2^{34}$.

$$
\begin{gathered}
\mathrm{O}_{\mathrm{x}}+n e^{-} \rightarrow \mathrm{R}_{\mathrm{ed}} \\
j=n F k_{b}^{0} a\left[\mathrm{R}_{\mathrm{ed}}\right] \exp [(1-\alpha) f \eta]-\mathrm{n} F k_{f}^{0} a\left[\mathrm{O}_{\mathrm{x}}\right] \exp [-\alpha f \eta]
\end{gathered}
$$

In Eq. $2, j$ is the current density; $\eta$ is the overpotential for the cathodic reaction; $k_{f}^{0}$ is the standard forward rate constant; $k_{b}{ }^{0}$ is the standard backward rate constant; $F$ is the Faraday constant; $f$ $=F / R T$, where $R$ is the ideal gas constant and $T$ is absolute temperature; $\alpha$ is the transfer coefficient assumed to be equal to $0.5 ; n$ is the number of transferred electrons; $a\left[\mathrm{R}_{\mathrm{ed}}\right]$ and $a\left[\mathrm{O}_{\mathrm{x}}\right]$ are the concentrations of reductant and oxidant.

When the overpotential is sufficiently high, i.e., $\exp [-(1-\alpha) f \eta]$ $<<\exp (-\alpha f \eta)$, the backward reaction can be ignored ${ }^{35}$. Even the high-performance $\mathrm{CO}_{2}$ electrolysis catalysts have sufficient overpotentials to meet this condition ${ }^{36}$. Therefore, Eq. 2 can be simplified to Eq. 3. At equilibrium conditions $(j=0)$, Eq. 2 can be simplified to Eq. 4.

$$
\begin{aligned}
& j=-n F k_{f}^{0} a\left[\mathrm{O}_{\mathrm{x}}\right] \exp (-\alpha f \eta) \\
& a\left[\mathrm{R}_{\mathrm{ed}}\right] / a\left[\mathrm{O}_{\mathrm{x}}\right]=K^{\theta} \exp (-f \eta)
\end{aligned}
$$

By combining Eq. 4 , the $a\left[\mathrm{O}_{\mathrm{x}}\right]$ in Eq. 3 can be represented by the concentration of reactants and $K^{\theta} \exp (-f \eta)$ in the previous step (see the supplementary information for more details). Subsequently, the rate expression of the two-electron transfer $\mathrm{CO}_{2} \mathrm{ER}$ with a specific reaction step as the RLS can be derived (Tables 1 and 2, different labels are assigned to the corresponding RLSs according to the reaction processes). Whether the RLS is controlled by ET, PT, PCET, or D is also shown in the Tables. One thing should also be kept in mind is that all these expressions are based on assumptions of what might happen in the mechanism, which may not cover all possible kinetic cases at current cognitive levels.

According to the rate expression, the reaction order of different reactants can be obtained. For example, when the adsorption of $\mathrm{CO}_{2}$ with the ET (step A1 in Table 1, Eq. 5) is the RLS for $\mathrm{CO}_{2} \mathrm{ER}$ to $\mathrm{CO}$,

$$
\mathrm{CO}_{2}+{ }^{*}+e^{-} \rightarrow{ }^{*} \mathrm{CO}_{2}^{-}
$$

the rate expression (Eq. 6) is

$$
j_{\text {co }}=2 F k_{A 1}^{0} a\left[\mathrm{CO}_{2}\right] \theta^{*} \exp (-\alpha f \eta) \text {, }
$$

where the corresponding reaction order of $\mathrm{H}^{+}$and $\mathrm{H}_{2} \mathrm{O}$ molecules should be 0 .

Thus, the RLS of two-electron transfer $\mathrm{CO}_{2} \mathrm{ER}$ could be determined via the analysis of the reaction order of the reactants $19,28,30,37$. Whether the reaction is controlled by the concentration of $\mathrm{H}^{+}$can be reflected by its $\mathrm{pH}$ dependency. However, whether protons are involved in the RLS cannot be simply determined by the $\mathrm{pH}$ dependency of the reaction, since $\mathrm{H}_{2} \mathrm{O}$ could be the proton source. Therefore, KIE experiments can be conducted to reveal if the $\mathrm{H}_{2} \mathrm{O}$ molecules are involved in the reaction as a proton source. It is noteworthy that possible RLS with the rate expression involving neither $\mathrm{H}^{+}$nor $\mathrm{H}_{2} \mathrm{O}$ may still be controlled by them because protons may take 


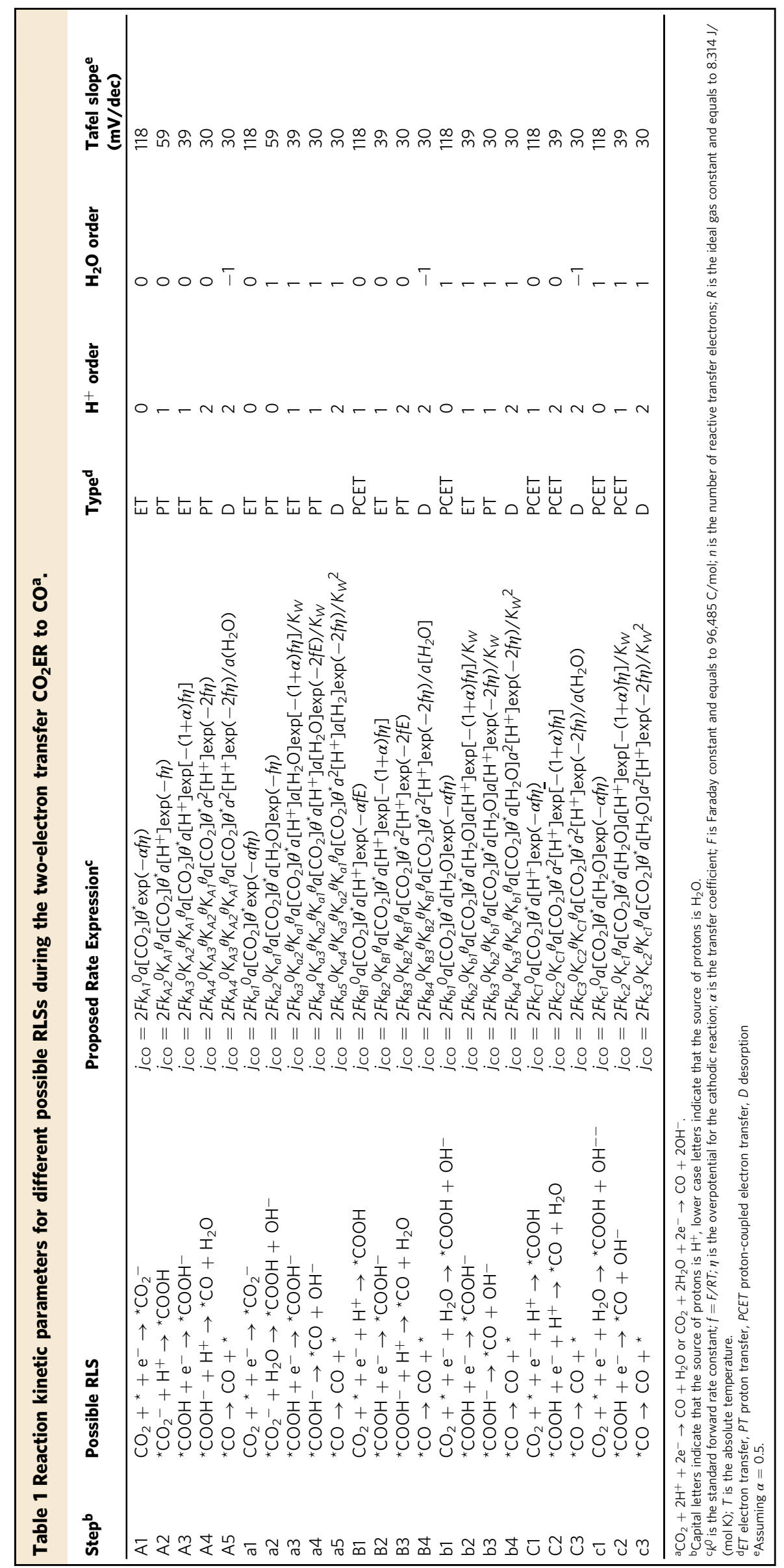




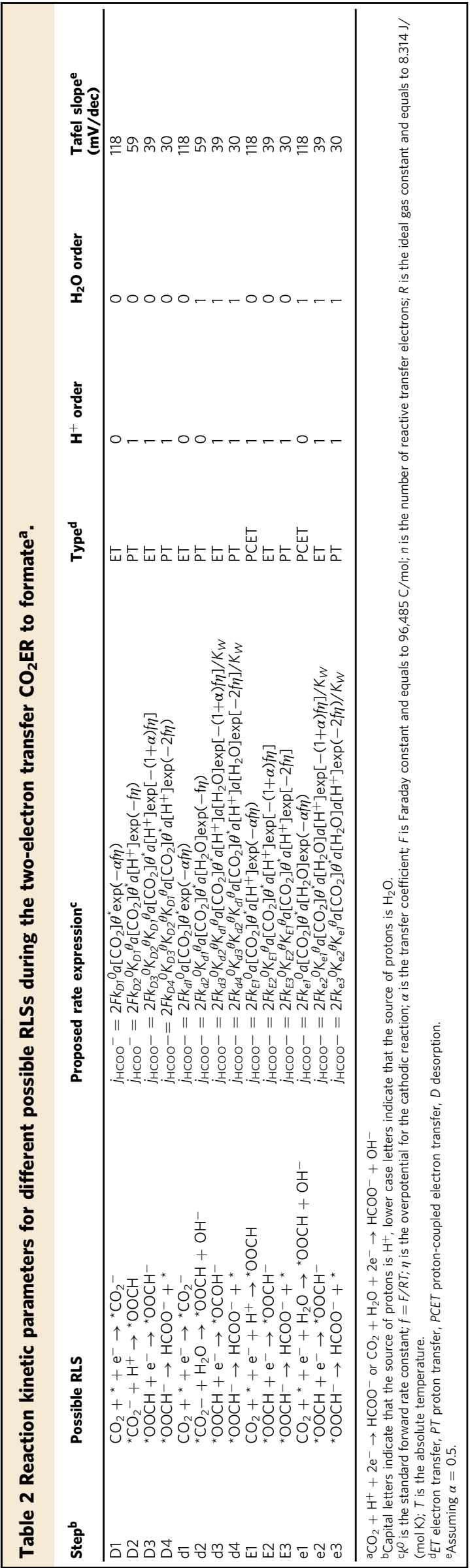

part in the reaction processes before the RLS (see the supplementary information for more details). Therefore, indepth reaction rate analysis is essential for the determination of the RLS.

The fabrication of model catalysts. To elucidate the RLS of twoelectron transfer $\mathrm{CO}_{2} \mathrm{ER}, \mathrm{Au}, \mathrm{Ag}, \mathrm{Sn}$, and In were chosen as model catalysts. Au and Ag have been proved to exhibit good performance for the production of $\mathrm{CO}$, and In and $\mathrm{Sn}$ are promising catalysts with high selectivity for formate ${ }^{38,39}$. These catalysts were deposited on $\mathrm{Si}(100)$ wafers by magnetron sputtering. To enhance the adhesion between the catalysts and the Si wafers, Ti films with a thickness of approximately $15 \mathrm{~nm}$ were first deposited on the $\mathrm{Si}$ wafers ${ }^{40}$. Catalysts with relatively high conductivity (i.e., Au and Ag) were directly deposited on the $\mathrm{Ti}$ films. The thicknesses of the catalyst films were controlled to be $200 \mathrm{~nm}$. Less conductive In and Sn catalyst films with a thickness of about $400 \mathrm{~nm}$ were deposited after the adhesion of $30 \mathrm{~nm}$ Au layers onto the Ti films. This strategy improves the conductivity of the substrate and preventes delamination of the films under cathodic potentials. Because of the high surface tension of Sn and In, thicker films need to be deposited to cover the substrates completely. According to scanning electron microscopy (SEM) images (Supplementary Fig. 1), the Au, Ag, In, and Sn catalyst films are evenly distributed over the substrates. X-ray diffraction (XRD) patterns (Supplementary Fig. 2) show that these films have polycrystalline structures. No signal of the substrate materials was found in the survey X-ray photoelectron spectroscopy (XPS) spectra of the samples, indicating that no substrate would be exposed to the electrolyte (Supplementary Fig. 3). Furthermore, the analyses of the surface valence states of the Au and Ag films show that they are primarily in the metallic state with only slight surface oxidation for Ag. However, the surfaces of the Sn and In films were oxidized (Supplementary Fig. 4). These four model catalysts were then used to study the RLS of two-electron transfer $\mathrm{CO}_{2}$ ER. Here, $\mathrm{CO}$ and $\mathrm{H}_{2}$ were the main products over $\mathrm{Ag}$ and $\mathrm{Au}$. $\mathrm{CO}$, formate, and $\mathrm{H}_{2}$ were the main products over $\mathrm{Sn}$ and In. The total Faradaic efficiency is basically equal to $100 \%$ (Supplementary Fig. 5).

Experimental determination of the RLS. In order to explore the impact of the $\mathrm{H}^{+}$concentration on the two-electron transfer $\mathrm{CO}_{2} \mathrm{ER}$, the changing trends of $j_{\mathrm{CO}}$ and $j_{\mathrm{HCOO}-}$ with the variation of electrolyte $\mathrm{pH}$ were analyzed. Experiments were carried out in a flowing $\mathrm{H}$-cell with five types of $\mathrm{CO}_{2}$ saturated electrolytes $(0.3 \mathrm{M}$ $\mathrm{KHCO}_{3}, \mathrm{pH} 7.0 ; 0.1 \mathrm{M} \mathrm{K}_{3} \mathrm{PO}_{4}, \mathrm{pH} 6.6 ; 0.1 \mathrm{M} \mathrm{KH}_{2} \mathrm{PO}_{4}, \mathrm{pH} 4.3 ; 0.1$ $\mathrm{M} \mathrm{KH} \mathrm{KO}_{4}+0.1 \mathrm{M} \mathrm{H}_{3} \mathrm{PO}_{4}, \mathrm{pH} 2.9 ; 0.1 \mathrm{M} \mathrm{H}_{3} \mathrm{PO}_{4}, \mathrm{pH}$ 1.6). Figure 1a-d show the $j_{\mathrm{CO}}$ of the four catalysts as a function of applied potential. The electrocatalytic activity for $\mathrm{CO}$ generation is barely affected by the $\mathrm{pH}$ of the electrolytes (Supplementary Fig. 6a). Since the $j_{\mathrm{CO}}$ is consistent under various $\mathrm{pH}$ from 2.9 to 7.0 , the reaction rate expression of $\mathrm{CO}_{2} \mathrm{ER}$ to $\mathrm{CO}$ should not include $\mathrm{H}^{+}$. Therefore, only the following reaction steps (Eqs. 7-9), with reaction order for $\mathrm{H}^{+}$to be 0 in the rate expressions, could possibly be the RLS.

$$
\begin{gathered}
\text { Al oral }: \mathrm{CO}_{2}+{ }^{*}+\mathrm{e}^{-} \rightarrow{ }^{*} \mathrm{CO}_{2}{ }^{-} \\
\text {a2 }:{ }^{*} \mathrm{CO}_{2}{ }^{-}+\mathrm{H}_{2} \mathrm{O} \rightarrow{ }^{*} \mathrm{COOH}+\mathrm{OH}^{-} \\
\text {b1 or cl }: \mathrm{CO}_{2}+{ }^{*}+e^{-}+\mathrm{H}_{2} \mathrm{O} \rightarrow{ }^{*} \mathrm{COOH}+\mathrm{OH}^{-}
\end{gathered}
$$

Similar to the case of $\mathrm{CO}$, the $j_{\mathrm{HCOO}}{ }^{-}$of both $\mathrm{Sn}$ and In did not show significant change with the electrolyte $\mathrm{pH}$ (Fig. 1e, $\mathrm{f}$ 

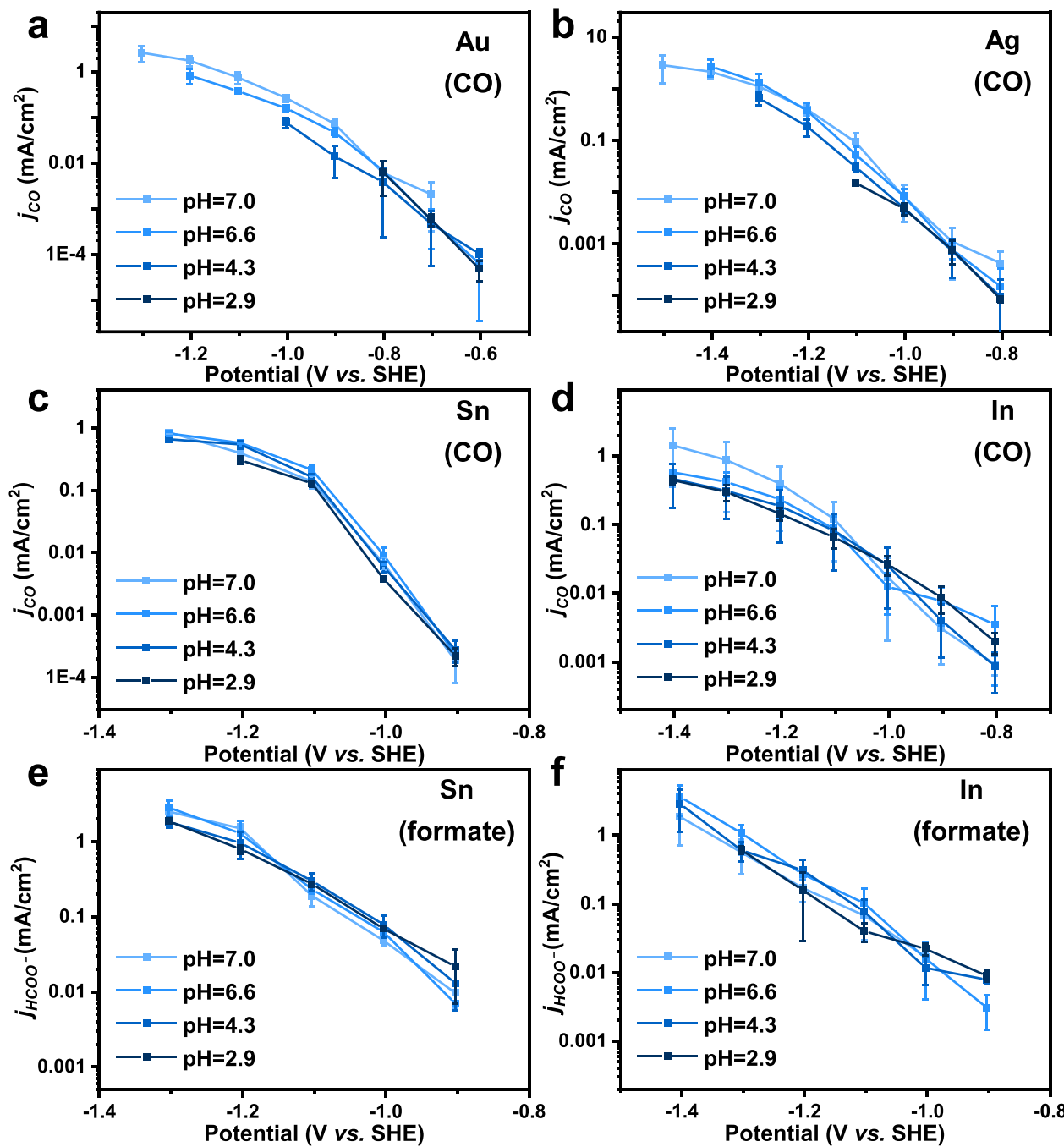

Fig. 1 The pH dependency for $\mathbf{C O}_{2}$ ER toward $\mathbf{C O}$ and formate. The $j_{\mathrm{CO}}$ for $\mathrm{Au}(\mathbf{a}), \mathrm{Ag}(\mathbf{b}), \mathrm{Sn}(\mathbf{c})$, and In (d) catalysts in electrolytes with different pH. The $j_{\mathrm{HCOO}}-$ for $\mathrm{Sn}(\mathbf{e})$ and $\ln (\mathbf{f})$ catalysts in electrolytes with different $\mathrm{pH}$. Error bars are means \pm standard deviation $(n=3$ replicates $)$.

and Supplementary Fig. 6b). Thus, the reaction order of $\mathrm{H}^{+}$for $\mathrm{CO}_{2}$ ER to formate should also be 0 . According to Table 2, the possible RLS meeting this requirement are listed as follows (Eqs. 10-12).

$$
\begin{gathered}
\text { D1 ord } 1: \mathrm{CO}_{2}+{ }^{*}+\mathrm{e}^{-} \rightarrow{ }^{*} \mathrm{CO}_{2}{ }^{-} \\
\mathrm{d} 2:{ }^{*} \mathrm{CO}_{2}{ }^{-}+\mathrm{H}_{2} \mathrm{O} \rightarrow{ }^{*} \mathrm{OOCH}+\mathrm{OH}^{-} \\
\mathrm{e} 1: \mathrm{CO}_{2}+{ }^{*}+\mathrm{e}^{-}+\mathrm{H}_{2} \mathrm{O} \rightarrow{ }^{*} \mathrm{OOCH}+\mathrm{OH}^{-}
\end{gathered}
$$

On the contrary, the activity of the hydrogen evolution reaction (HER) is enhanced as the $\mathrm{pH}$ decreases (Fig. 2 and Supplementary Fig. 7). This phenomenon indicates that the RLS of HER depends on the concentration of $\mathrm{H}^{+}$, which is consistent with the results from the literatures ${ }^{30,41}$. This result further supports the feasibility of revealing the RLS of two-electron transfer $\mathrm{CO}_{2} \mathrm{ER}$ by $\mathrm{pH}$ dependency.

Considering the inevitable deviation of the bulk $\mathrm{pH}$ and local $\mathrm{pH}$ caused by the constant consumption of protons during $\mathrm{CO}_{2} \mathrm{ER}$ and HER, the local $\mathrm{pH}$ was investigated. Supplementary Fig. 9 shows the local $\mathrm{pH}$ as a function of the operating potential for In (see the note of Supplementary Fig. 9 for the reason why choosing
In as the representative catalyst). The local $\mathrm{pH}$ elevates slowly with the increase of the reaction potential in different electrolytes. However, the order of the local $\mathrm{pH}$ is the same as that of the bulk $\mathrm{pH}$. Therefore, it is reasonable to use bulk $\mathrm{pH}$ in the current work. Also, regarding the inevitable change of ion concentration when changing $\mathrm{pH}$, comparative experiments in 0.1 and $0.3 \mathrm{M} \mathrm{KH}_{2} \mathrm{PO}_{4}$ show the $j_{\mathrm{CO}}$ and $j_{\mathrm{HCOO}}{ }^{-}$are basically the same (Supplementary Fig. 10), indicating the change in the concentrations of potassium and phosphate has little effect on the $\mathrm{CO}_{2} \mathrm{ER}$ activity in those experiments. So, the ion concentration caused by changing the $\mathrm{pH}$ will not affect the conclusion.

The $\mathrm{pH}$ dependency experiments eliminated many potential RLSs. To further determine the RLS, KIE experiments were considered to analyze whether water molecules are involved in the rate expression. Since the KIE of $\mathrm{CO}_{2} \mathrm{ER}$ in homogeneous catalysts was tested to be $6.92^{42}$ and $8.2^{43}$ for $\mathrm{CO}$ and formate, respectively, which means if proton was involved in the RLS for $\mathrm{CO}_{2} \mathrm{ER}$ to $\mathrm{CO}$ or formate, the KIE should be $>1$. Secondly, the KIE was used to exclude the step of $\mathrm{H}_{2} \mathrm{O}$ providing proton, where the KIE of $\mathrm{H}_{2} \mathrm{O}$ dissociation are around $3.4-7.6^{44}$, so the involvement of protons in the RLS of $\mathrm{CO}_{2} \mathrm{ER}$ should show the KIE $>1$. Thirdly, KIE experiments have been known to lead to 

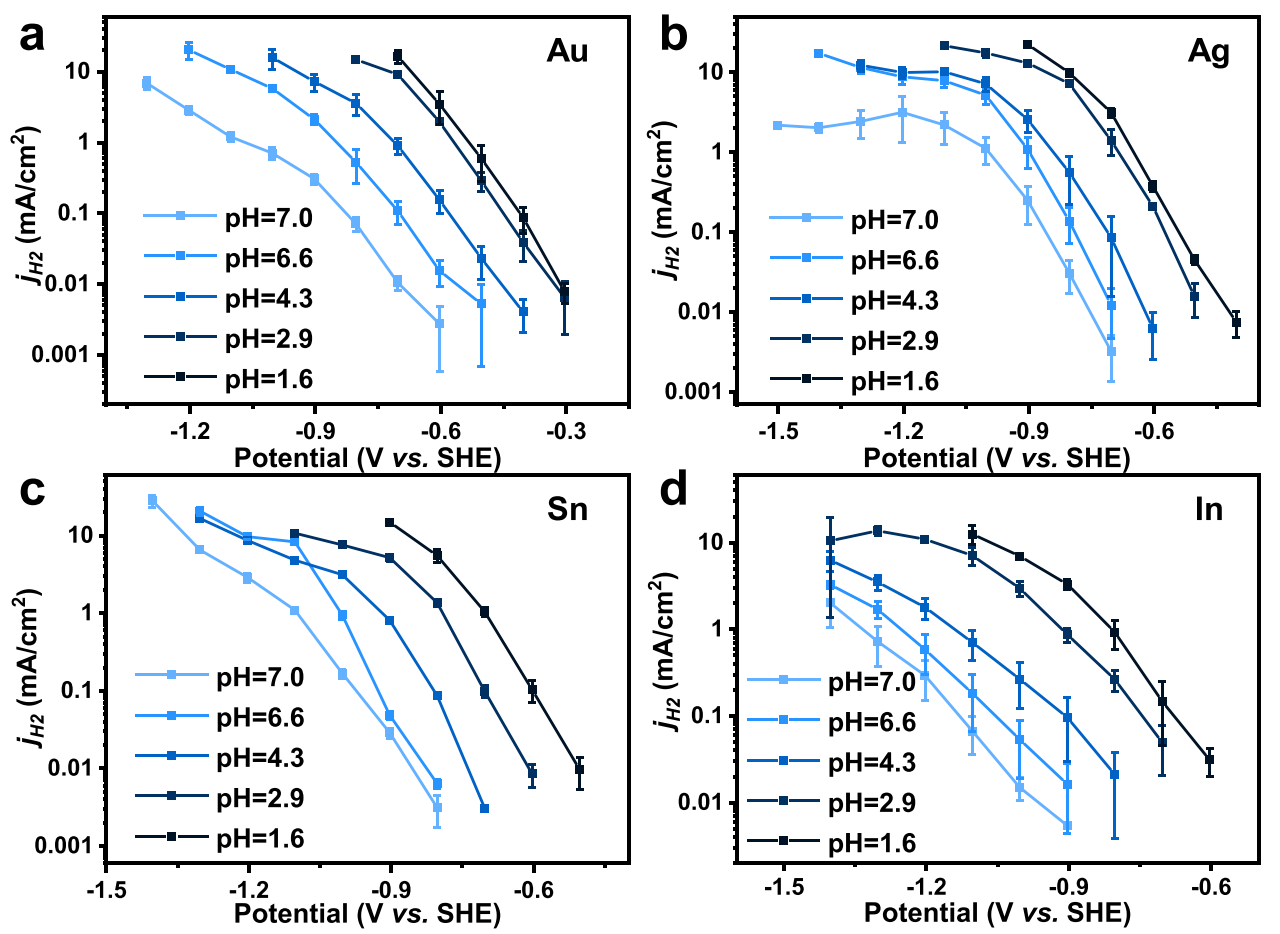

Fig. 2 The pH dependency for HER. The $j_{H 2}$ for $\mathrm{Au}(\mathbf{a}), \mathrm{Ag}(\mathbf{b}), \mathrm{Sn}(\mathbf{c})$, and In (d) catalysts in electrolytes with different pH. Error bars are means \pm standard deviation ( $n=3$ replicates).

false-negative conclusions, but only in very specific and rare instancesnormally involving more environment-sensitive molecular catalysts ${ }^{45}$. To the best of our knowledge, there have been no calculation on transition-metal catalysts showing $\mathrm{D}_{2} \mathrm{O}$ could distort $\mathrm{CO}_{2}$ electrolysis results for two-electron products compared to using $\mathrm{H}_{2} \mathrm{O}$. Therefore, it seems reasonable to use KIE to explore whether water molecules are involved in the rate expression.

In the KIE experiments, both $j_{\mathrm{CO}}$ and $j_{\mathrm{HCOO}}{ }^{-}$did not change with the use of $\mathrm{D}_{2} \mathrm{O}$ instead of $\mathrm{H}_{2} \mathrm{O}$ in the $0.1 \mathrm{M}$ $\mathrm{KH}_{2} \mathrm{PO}_{4}$ electrolyte for $\mathrm{Au}, \mathrm{Ag}, \mathrm{Sn}$, and In catalysts (Fig. 3). To eliminate the possibility that $\mathrm{KH}_{2} \mathrm{PO}_{4}$ provides protons that equilibrate with $\mathrm{D}_{2} \mathrm{O}$ to generate a small amount of $\mathrm{H}_{2} \mathrm{O}$, $\mathrm{K}_{2} \mathrm{CO}_{3}$ solutions in $\mathrm{H}_{2} \mathrm{O}$ and $\mathrm{D}_{2} \mathrm{O}$ were also chosen as electrolytes. The results of activity tests with the In catalyst show that $j_{\mathrm{CO}}$ and $j_{\mathrm{HCOO}}{ }^{-}$are almost the same in both electrolytes (Supplementary Fig. 11a,b). These phenomena demonstrate that the reaction order of $\mathrm{H}_{2} \mathrm{O}$ for $\mathrm{CO}_{2} \mathrm{ER}$ to $\mathrm{CO}$ or formate should be 0 . Combining this knowledge with the results of $\mathrm{pH}$ dependency studies, the RLS of both the twoelectron transfer $\mathrm{CO}_{2} \mathrm{ER}$ to $\mathrm{CO}$ and formate is deduced to be the adsorption of $\mathrm{CO}_{2}$ with one electron transferred simultaneously, as shown in Eqs. 7 and 10, respectively. KIE experiments for HER were also conducted with the Au, Ag, $\mathrm{Sn}$, and In catalysts. When $\mathrm{D}_{2} \mathrm{O}$ was used in the solvent, the $j_{\mathrm{H} 2}$ drops significantly (Fig. 4 and Supplementary Fig. 11c), indicating water molecules are a part of the RLS or take part in the reaction process before the RLS, which is also consistent with previous reports ${ }^{46}$. It should be noticed that the $\mathrm{pH}$ dependency and KIE experiments were not conducted in alkaline electrolytes since the solution would become neutral or acidic after the dissolution of $\mathrm{CO}_{2}{ }^{47}$, but we think the conclusion might also be applicable to alkaline solutions (see Supplementary Figs. 12 and 13 for detailed explanation).
Based on the above analyses, the RLS of two-electron transfer $\mathrm{CO}_{2} \mathrm{ER}$ for $\mathrm{Au}, \mathrm{Ag}, \mathrm{Sn}$, and In catalysts was found to be the adsorption of $\mathrm{CO}_{2}$ with the concomitant ET. Since the transfer of electrons is quite fast over metal catalysts ${ }^{28,48}$, the ultimate RLS is proposed to be most likely the adsorption of $\mathrm{CO}_{2}$.

\section{Discussion}

In summary, this work presents an effective approach to determine the RLS by employing a detailed analysis of the reaction rate expression together with $\mathrm{pH}$ dependency and KIE experiments. It was found that both $j_{\mathrm{CO}}$ and $j_{\mathrm{HCOO}}{ }^{-}$are independent of the $\mathrm{pH}$ and deuteration of the electrolytes for $\mathrm{Au}, \mathrm{Ag}, \mathrm{Sn}$, and In, which are representative catalysts for two-electron transfer $\mathrm{CO}_{2} \mathrm{ER}$. The results reveal that the RLS of the two-electron $\mathrm{CO}_{2} \mathrm{ER}$ should be the adsorption of $\mathrm{CO}_{2}$. This finding suggests effective strategies to design highly active $\mathrm{CO}_{2} \mathrm{ER}$ catalyst for the production of $\mathrm{CO}$ and formate.

\section{Methods}

Electrode preparation. Au, Ag, In, and Sn thin films were deposited onto singlecrystal Si wafers with the (100) orientation using an AJA ATC Orion-5 magnetron sputtering system. Before the deposition, the Si wafers were etched with $\mathrm{Ar}^{+}$ions for $5 \mathrm{~min}$ with a power of $40 \mathrm{~W}$ to clean the silicon oxide on Si wafers. Then, $15 \mathrm{~nm}$ Ti films were deposited as binders between catalysts and Si wafers at the power of $130 \mathrm{~W}$. Au and Ag catalyst films with the thickness of about $200 \mathrm{~nm}$ were deposited over $\mathrm{Ti}$ at $50 \mathrm{~W}$. Due to the poor electrical conductivity of In and Sn catalysts, $\mathrm{Au}$ films $(30 \mathrm{~nm})$ were added over Ti before depositing $400 \mathrm{~nm}$ of the catalyst films at $20 \mathrm{~W}$.

Electrode characterization. The crystal structures of the $\mathrm{Au}, \mathrm{Ag}$, In, and $\mathrm{Sn}$ thin films were analyzed with a Rigaku Smartlab X-ray diffractometer (XRD) using $\mathrm{Cu} \mathrm{Ka}$ radiation $(40 \mathrm{kV}, 40 \mathrm{~mA})$. The near-surface compositions of the thin films were measured with a Kratos Axis Ultra DLD X-ray photoelectron spectrometer (XPS). All spectra were acquired using monochromatized $\mathrm{Al} \mathrm{Ka}$ radiation $(15 \mathrm{kV}, 15 \mathrm{~mA})$. The kinetic energy scale of the measured spectra was calibrated by setting the $\mathrm{C} 1 \mathrm{~s}$ binding energy to $284.8 \mathrm{eV}$. The surface structure 

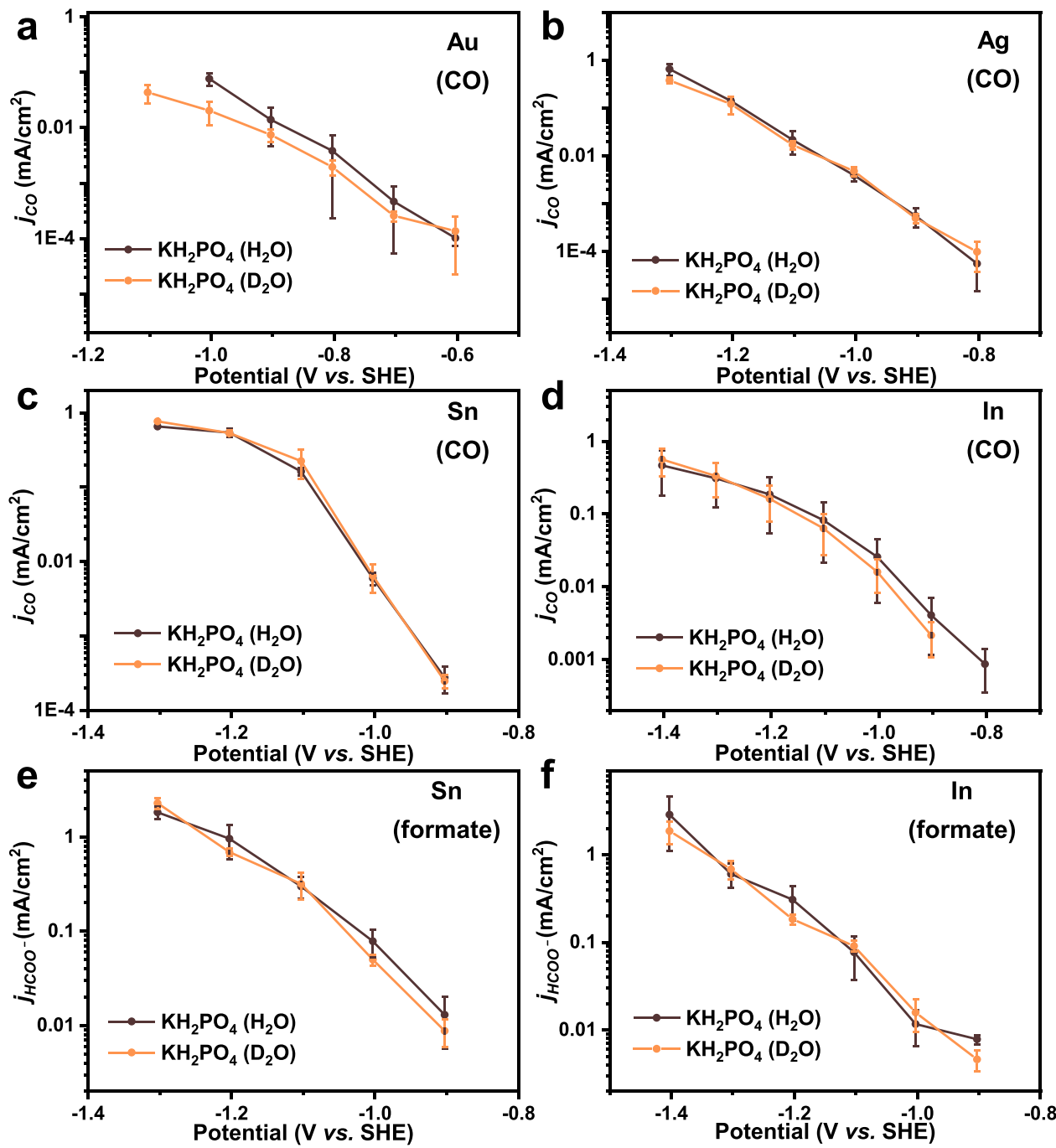

Fig. 3 Kinetic isotope effect for $\mathbf{C O}_{2}$ ER toward $\mathbf{C O}$ and formate. The $j_{\mathrm{CO}}$ for $\mathrm{Au}(\mathbf{a}), \mathrm{Ag}(\mathbf{b}), \mathrm{Sn}(\mathbf{c})$, and $\ln (\mathbf{d})$ in $0.1 \mathrm{M} \mathrm{KH}_{2} \mathrm{PO}_{4}$ electrolytes with $\mathrm{D}_{2} \mathrm{O}$ and $\mathrm{H}_{2} \mathrm{O}$. The $j_{\mathrm{HCOO}}{ }^{-}$for $\mathrm{Sn}(\mathbf{e})$ and $\ln (\mathbf{f})$ in $0.1 \mathrm{M} \mathrm{KH}_{2} \mathrm{PO}_{4}$ electrolytes with $\mathrm{D}_{2} \mathrm{O}$ and $\mathrm{H}_{2} \mathrm{O}$. Error bars are means \pm standard deviation $(n=3$ replicates).

of those thin films was recorded using an FEI XL30 Sirion scanning electron microscope (SEM) at the $5 \mathrm{kV}$ acceleration voltage, Everhart-Thornley detector, secondary electrons mode.

Electrochemical characterization. All electrochemical activity measurements were conducted in a custom electrochemical cell machined from PEEK at room temperature and atmospheric pressure. The cell was sonicated in $20 \mathrm{wt} \%$ nitric acid and thoroughly rinsed with DI water before all experimentation. The working and counter electrodes were parallel and separated by a bipolar membrane (Fumasep FBM). The exposed geometric surface area of each electrode was $1 \mathrm{~cm}^{2}$. The electrolyte volumes in the cathodic and anodic chambers were $6 \mathrm{~mL}$ and $1 \mathrm{~mL}$, respectively. The counter electrode was iridium dioxide $\left(\mathrm{IrO}_{2}\right)$ purchased from Dioxide Materials. The working electrode potential was referenced against a miniature $\mathrm{Ag} / \mathrm{AgCl}$ electrode (Innovative Instruments Inc.) that was calibrated against a homemade standard hydrogen electrode (SHE). 0.3 M potassium bicarbonate $\left(\mathrm{KHCO}_{3}\right.$, Sigma Aldrich $99.7 \%$, pH 7.0), 0.1 M potassium phosphate $\left(\mathrm{K}_{3} \mathrm{PO}_{4}\right.$, Sigma Aldrich 99.99\%, pH 6.6), $0.1 \mathrm{M}$ monopotassium phosphate $\left(\mathrm{KH}_{2} \mathrm{PO}_{4}\right.$, Sigma Aldrich $99.99 \%$, pH 4.3), $0.1 \mathrm{M}$ monopotassium phosphate adjusted the $\mathrm{pH}$ with 0.1 phosphoric acid $\left(\mathrm{KH}_{2} \mathrm{PO}_{3}\right.$ with $\mathrm{H}_{3} \mathrm{PO}_{4}$, pH 2.9$)$ and $0.1 \mathrm{M}$ phosphoric acid $\left(\mathrm{H}_{3} \mathrm{PO}_{4}\right.$, Sigma Aldrich $85 \% \mathrm{w} / \mathrm{w}, \mathrm{pH} 1.6$ ) solutions prepared using $18.2 \mathrm{M} \Omega \cdot \mathrm{cm}$ Milli-Q water were used as the cathodic electrolyte. $0.1 \mathrm{M} \mathrm{KH}_{2} \mathrm{PO}_{4}$ was used as the anodic electrolyte. Metallic impurities in the as-prepared electrolytes were removed before electrolysis by chelating them with Chelex 100 (Sigma Aldrich). The cathodic electrolyte was sparged with $\mathrm{CO}_{2}$ (99.999\% Praxair Inc.) at a rate of $10 \mathrm{sccm}$ for $30 \mathrm{~min}$ prior to the experiments. Then $\mathrm{CO}_{2}$ was pumped into the cathodic chamber by using a peristaltic pump (SHENCHEN LabN6) with the rate of $130 \mathrm{rev} / \mathrm{min}$. Here, the experiments process in this pump speed cannot be the significantly diffusion-limited, since we have obtained relatively straight Tafel slopes over three orders of magnitude in current (Figs. 1-4). The pH values of electrolytes were measured in $\mathrm{CO}_{2}$ saturated solutions.

The produced $\mathrm{CO}$ and $\mathrm{H}_{2}$ were tested by gas chromatography (GC, Thermo scientific, TRACE 1300). Ar was used as the carrier gas. The GC was equipped with a packed Molsieve 5A column, a packed Hayesep Q column, and a RtQbond column to separate the gaseous products. Thus, $\mathrm{H}_{2}$ and $\mathrm{CO}$ could be identified using a thermal conductivity detector and a flame ionization detector, respectively. The liquid-phase products were analyzed after the electrolysis using a high-performance liquid chromatography (HPLC, Agilent 1200 series). Liquid-phase products were separated by an Aminex HPX-87H column (Bio-Rad) that was maintained at $50^{\circ} \mathrm{C}$. The HPLC was equipped with a diode array detector (DAD) and a refractive index detector (RID). The response signals of the DAD and RID were calibrated by solutions with different concentrations.

Electrochemical characterizations were performed using a Biologic VSP-300 potentiostat. All electrochemical measurements were recorded versus the reference electrode and converted to the SHE scale. Current interrupt was used to determine the uncompensated resistance $\left(R_{\mathrm{u}}\right)$ of the electrochemical cell. The accurate potentials were corrected according to the $R_{\mathrm{u}}$ (see Supplementary Table 3 for detailed potential correction process).

The electrocatalytic activity of the thin films was assessed by conducting chronoamperometry with a step length of $10 \mathrm{~min}$. Each thin film was tested at least three separate times to ensure statistical relevance of the observed trends. The Faradaic efficiency and partial current density calculation process can be found in Supplementary information. 

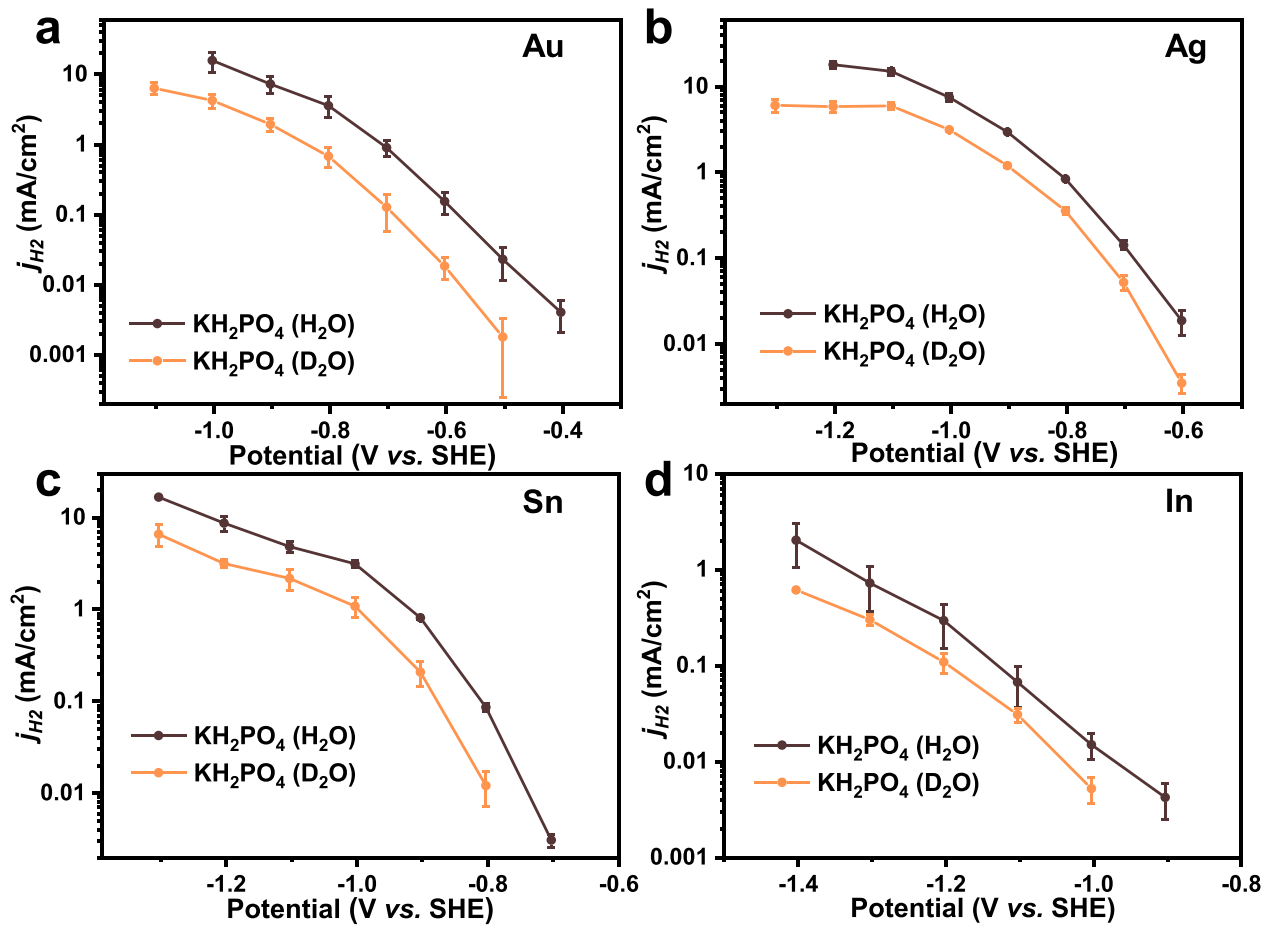

Fig. 4 Kinetic isotope effect for HER. The $j_{\mathrm{H} 2}$ for $\mathrm{Au}(\mathbf{a}), \mathrm{Ag}(\mathbf{b}), \mathrm{Sn}(\mathbf{c})$ and $\ln (\mathbf{d})$. The data were obtained from running $\mathrm{CO}_{2} \mathrm{ER}$ experiments at $0.1 \mathrm{M}$ $\mathrm{KH}_{2} \mathrm{PO}_{4}$ electrolyte with $\mathrm{D}_{2} \mathrm{O}$ and $\mathrm{H}_{2} \mathrm{O}$. Error bars are means \pm standard deviation ( $n=3$ replicates).

\section{Data availability}

All the data that support the findings of this study are available within the paper and its supplementary information files, or from the corresponding author on reasonable request.

Received: 6 December 2021; Accepted: 24 January 2022;

Published online: 10 February 2022

\section{References}

1. Peterson, A. A., Abild-Pedersen, F., Studt, F., Rossmeisl, J. \& Nørskov, J. K. How copper catalyzes the electroreduction of carbon dioxide into hydrocarbon fuels. Energy Environ. Sci. 3, 1311-1315 (2010).

2. Chen, C., Khosrowabadi Kotyk, J. F. \& Sheehan, S. W. Progress toward commercial application of electrochemical carbon dioxide reduction. Chem 4, 2571-2586 (2018).

3. Kibria, M. G. et al. Electrochemical $\mathrm{CO}_{2}$ reduction into chemical feedstocks: from mechanistic electrocatalysis models to system design. Adv. Mater. 31, e1807166 (2019).

4. Aresta, M., Dibenedetto, A. \& Angelini, A. Catalysis for the valorization of exhaust carbon: from $\mathrm{CO}_{2}$ to chemicals, materials, and fuels. technological use of $\mathrm{CO}_{2}$. Chem. Rev. 114, 1709-1742 (2014).

5. Fan, L. et al. Strategies in catalysts and electrolyzer design for electrochemical $\mathrm{CO}_{2}$ reduction toward $\mathrm{C}_{2+}$ products. Sci. Adv. 6, eaay3111 (2020).

6. Ling, Y., Ma, Q., Yu, Y. \& Zhang, B. Optimization strategies for selective $\mathrm{CO}_{2}$ electroreduction to fuels. Trans. Tianjin Univ. 27, 180-200 (2021).

7. Gao, D., Aran-Ais, R. M., Jeon, H. S. \& Cuenya, B. R. Rational catalyst and electrolyte design for $\mathrm{CO}_{2}$ electroreduction towards multicarbon products. Nat. Catal. 2, 198-210 (2019).

8. Ross, M. B. et al. Electrocatalytic rate alignment enhances syngas generation. Joule 3, 257-264 (2019).

9. Jouny, M., Luc, W. \& Jiao, F. General techno-economic analysis of $\mathrm{CO}_{2}$ electrolysis systems. Ind. Eng. Chem. Res. 57, 2165-2177 (2018).

10. Hernández, S. et al. Syngas production from electrochemical reduction of $\mathrm{CO}_{2}$ : current status and prospective implementation. Green. Chem. 19, 2326-2346 (2017).

11. Han, N., Ding, P., He, L., Li, Y. \& Li, Y. Promises of main group metal-based nanostructured materials for electrochemical $\mathrm{CO}_{2}$ reduction to formate. $A d v$. Energy Mater. 10, 1902338 (2019).
12. Zhang, Y. et al. Direct detection of electron transfer reactions underpinning the tin-catalyzed electrochemical reduction of $\mathrm{CO}_{2}$ using Fourier-transformed ac voltammetry. ACS Catal. 7, 4846-4853 (2017).

13. Zhang, B. A., Ozel, T., Elias, J. S., Costentin, C. \& Nocera, D. G. Interplay of homogeneous reactions, mass transport, and kinetics in determining selectivity of the reduction of $\mathrm{CO}_{2}$ on gold electrodes. ACS Cent. Sci. 5, 1097-1105 (2019).

14. Singh, M. R., Goodpaster, J. D., Weber, A. Z., Head-Gordon, M. \& Bell, A. T. Mechanistic insights into electrochemical reduction of $\mathrm{CO}_{2}$ over Ag using density functional theory and transport models. Proc. Natl Acad. Sci. USA 114, E8812-E8821 (2017).

15. Rosen, J. et al. Mechanistic insights into the electrochemical reduction of $\mathrm{CO}_{2}$ to CO on nanostructured Ag surfaces. ACS Catal. 5, 4293-4299 (2015).

16. Dunwell, M., Luc, W., Yan, Y., Jiao, F. \& Xu, B. Understanding surfacemediated electrochemical reactions: $\mathrm{CO}_{2}$ reduction and beyond. ACS Catal. 8 , 8121-8129 (2018).

17. Gu, J., Heroguel, F., Luterbacher, J. \& Hu, X. L. Densely packed, ultra small $\mathrm{SnO}$ nanoparticles for enhanced activity and selectivity in electrochemical $\mathrm{CO}_{2}$ reduction. Angew. Chem. Int. Ed. 57, 2943-2947 (2018).

18. Liu, S. B. et al. Shape-dependent electrocatalytic reduction of $\mathrm{CO}_{2}$ to $\mathrm{CO}$ on triangular silver nanoplates. J. Am. Chem. Soc. 139, 2160-2163 (2017).

19. Varela, A. S. et al. pH effects on the selectivity of the electrocatalytic $\mathrm{CO}_{2}$ reduction on graphene-embedded $\mathrm{Fe}-\mathrm{N}-\mathrm{C}$ motifs: Bridging concepts between molecular homogeneous and solid-state heterogeneous catalysis. ACS Energy Lett. 3, 812-817 (2018).

20. Verma, S. et al. Insights into the low overpotential electroreduction of $\mathrm{CO}_{2}$ to $\mathrm{CO}$ on a supported gold catalyst in an alkaline flow electrolyzer. Acs Energy Lett. 3, 193-198 (2018).

21. Lu, Q. et al. A selective and efficient electrocatalyst for carbon dioxide reduction. Nat. Commun. 5, 3242 (2014).

22. Lu, X., Yu, T., Wang, H., Qian, L. \& Lei, P. Electrochemical fabrication and reactivation of nanoporous gold with abundant surface steps for $\mathrm{CO}_{2}$ reduction. ACS Catal. 10, 8860-8869 (2020).

23. Shi, H., Cheng, Y. \& Kang, P. Metal oxide/nitrogen-doped carbon catalysts enables highly efficient $\mathrm{CO}_{2}$ electroreduction. Trans. Tianjin Univ. 27, 269-277 (2021).

24. Firet, N. J. \& Smith, W. A. Probing the reaction mechanism of $\mathrm{CO}_{2}$ electroreduction over Ag films via operando infrared spectroscopy. ACS Catal. 7, 606-612 (2017)

25. Liu, H., Liu, J. \& Yang, B. Modeling the effect of surface CO coverage on the electrocatalytic reduction of $\mathrm{CO}_{2}$ to $\mathrm{CO}$ on Pd surfaces. Phys. Chem. Chem. Phys. 21, 9876-9882 (2019). 
26. Gao, D. et al. Size-dependent electrocatalytic reduction of $\mathrm{CO}_{2}$ over Pd nanoparticles. J. Am. Chem. Soc. 137, 4288-4291 (2015).

27. Limaye, A. M., Zeng, J. S., Willard, A. P. \& Manthiram, K. Bayesian data analysis reveals no preference for cardinal Tafel slopes in $\mathrm{CO}_{2}$ reduction electrocatalysis. Nat. Commun. 12, 703 (2021).

28. Vijay, S. et al. Dipole-field interactions determine the $\mathrm{CO}_{2}$ reduction activity of 2D Fe-N-C single-atom catalysts. ACS Catal. 10, 7826-7835 (2020).

29. Hori, Y. \& Suzuki, S. Electrolytic reduction of carbon dioxide at mercury electrode in aqueous solution. Bull. Chem. Soc. Jpn. 55, 660-665 (1982).

30. Strmcnik, D. et al. Improving the hydrogen oxidation reaction rate by promotion of hydroxyl adsorption. Nat. Chem. 5, 300-306 (2013).

31. Burke, K. Perspective on density functional theory. J. Chem. Phys. 136, 150901 (2012).

32. Cohen, A. J., Mori-Sanchez, P. \& Yang, W. T. Challenges for density functional theory. Chem. Rev. 112, 289-320 (2012).

33. Adler, S. B. Sources of cell and electrode polarisation losses in SOFCs. In: High-Temperature Solid Oxide Fuel Cells for the 21st Century (Second Edition) (eds Kendall, K. \& Kendall, M.) (Academic Press, 2016).

34. Newman, J. \& Thomas-Alyea, K. E. Electrochemical Systems (John Wiley \& Sons, 2004).

35. Bard, A. J. \& Faulkner, L. R. Fundamentals and applications. Electrochem. Methods 2, 580-632 (2001).

36. Larrazábal, G. O., Martín, A. J. \& Pérez-Ramírez, J. Building blocks for high performance in electrocatalytic $\mathrm{CO}_{2}$ reduction: materials, optimization strategies, and device engineering. J. Phys. Chem. Lett. 8, 3933-3944 (2017)

37. Ringe, $\mathrm{S}$. et al. Double layer charging driven carbon dioxide adsorption limits the rate of electrochemical carbon dioxide reduction on gold. Nat. Commun. 11, 33 (2020).

38. Zhu, D. D., Liu, J. L. \& Qiao, S. Z. Recent advances in inorganic heterogeneous electrocatalysts for reduction of carbon dioxide. Adv. Mater. 28, 3423-3452 (2016).

39. Yin, Z., Palmore, G. T. R. \& Sun, S. Electrochemical reduction of $\mathrm{CO}_{2}$ catalyzed by metal nanocatalysts. Trends Chem. 1, 739-750 (2019).

40. Todeschini, M., Bastos da Silva Fanta, A., Jensen, F., Wagner, J. B. \& Han, A. Influence of $\mathrm{Ti}$ and $\mathrm{Cr}$ adhesion layers on ultrathin Au films. ACS Appl. Mater. Interfaces 9, 37374-37385 (2017).

41. Goyal, A. \& Koper, M. T. M. The interrelated effect of cations and electrolyte $\mathrm{pH}$ on the hydrogen evolution reaction on gold electrodes in alkaline media. Angew. Chem. Int. Ed. 60, 13452-13462 (2021).

42. Devi, N., Williams, C. K., Chaturvedi, A. \& Jiang, J. J. Homogeneous electrocatalytic $\mathrm{CO}_{2}$ reduction using a porphyrin complex with flexible triazole units in the second coordination sphere. ACS Appl. Energy Mater. 4, 3604-3611 (2021).

43. Dey, S., Todorova, T. K., Fontecave, M. \& Mougel, V. Electroreduction of $\mathrm{CO}_{2}$ to formate with low overpotential using cobalt pyridine thiolate complexes. Angew. Chem. Int. Ed. 59, 15726-15733 (2020).

44. German, E. D. \& Sheintuch, M. Quantum effects in the kinetics of $\mathrm{H}_{2} \mathrm{O}$ dissociative adsorption on $\mathrm{Pt}(111), \mathrm{Cu}(111), \mathrm{Rh}(111)$, and $\mathrm{Ni}(111)$. J. Phys. Chem. C. 114, 3089-3097 (2010).

45. Huynh, M. T. et al. Concerted one-electron two-proton transfer processes in models inspired by the tyr-his couple of photosystem II. ACS Cent. Sci. 3, 372-380 (2017).

46. Tian, X., Zhao, P. \& Sheng, W. Hydrogen evolution and oxidation: mechanistic studies and material advances. Adv. Mater. 31, e1808066 (2019).

47. Butler, J. N. Carbon Dioxide Equilibria and Their Applications (Routledge, 2019).
48. Gauthier, J. A. et al. Facile electron transfer to $\mathrm{CO}_{2}$ during adsorption at the metal/solution interface. J. Phys. Chem. C. 123, 29278-29283 (2019).

\section{Acknowledgements}

B.S. acknowledges funding support from the Villum Foundation V-SUSTAIN Grant 9455. J.L.G. acknowledges the National Key R\&D Program of China (2021YFA1501503), the National Natural Science Foundation of China (22121004, 22038009), the Program of Introducing Talents of Discipline to Universities (BP0618007), and the Xplorer Prize. W.D. acknowledges the China Scholarship Council for financial support. We would like to express our gratitude to all those who helped us finish this work, including Ib Chorkendorff, Clark Ezra Lee, Moss Asger Barkholt, Degenhart Hochfilzer, and Yu Qiao from the Department of Physics in Technical University of Denmark, as well as Tuo Wang, Dongfang Cheng, Lulu Li and Tenghui Yuan from School of Chemical Engineering and Technology in Tianjin University.

\section{Author contributions}

W.D. conceived the idea and performed all the electrochemical experiments and characterizations. B.S. and J.G. supervised the research. All authors contributed to the manuscript before submission.

\section{Competing interests}

The authors declare no competing interests.

\section{Additional information}

Supplementary information The online version contains supplementary material available at https://doi.org/10.1038/s41467-022-28436-z.

Correspondence and requests for materials should be addressed to Brian Seger or Jinlong Gong.

Peer review information Nature Communications thanks Bo Yang, and the other, anonymous, reviewer(s) for their contribution to the peer review of this work. Peer reviewer reports are available.

Reprints and permission information is available at http://www.nature.com/reprints

Publisher's note Springer Nature remains neutral with regard to jurisdictional claims in published maps and institutional affiliations. (c) (i) Open Access This article is licensed under a Creative Commons adaptation, distribution and reproduction in any medium or format, as long as you give appropriate credit to the original author(s) and the source, provide a link to the Creative Commons license, and indicate if changes were made. The images or other third party material in this article are included in the article's Creative Commons license, unless indicated otherwise in a credit line to the material. If material is not included in the article's Creative Commons license and your intended use is not permitted by statutory regulation or exceeds the permitted use, you will need to obtain permission directly from the copyright holder. To view a copy of this license, visit http://creativecommons.org/ licenses/by/4.0/.

(C) The Author(s) 2022 